\title{
LEARNING DESIGN OPERATION MULTIPLICATION ALGEBRA USING WATER CONTEXT, OIL AND STONE STUDENTS CLASS V
}

\author{
Rahmawati Suandi ${ }^{1)}$ \\ ${ }^{1}$ Universitas PGRI Palembang \\ Email: rahmawatisuandi@yahoo.co.id
}

\begin{abstract}
The purpose of this study resulted in the learning path of students of algebraic multiplication materials by using water, oil and stone that evolved from informal to formal forms. The method used is a research design consisting of three stages, namely preliminary, design experiment and retrospective analysis. A series of lessons are designed and developed based on conjectures from the learning process and PMRI approach. This research was conducted in SMP N 5 Palembang involving 30 students of class VII. Learning Trajectory (LT) obtained includes three activities that are activities 1. Introduce the objects around that can be used in learning algebraic multiplication such as oil, stone and water, 2 Finding the Concept of Multiplication Algebra and 3. Solving problems related to daily life. The results of the experimental learning show that a series of activities that have been done helps to improve students' understanding of algebraic multiplication learning.
\end{abstract}

Keywords: Design research, Multiplication of Algebra, Oil,Stone and Water

\section{PENDAHULUAN}

Aljabar telah menjadi bagian penting dalam pendidikan(McClung, 1998). Aljabar menjadi salah satu kompetensi dalam matematika yang penting diajarkan dan dikuasai siswa dari Sekolah Dasar hingga tingkat menengah mengingat kemampuan mengoperasikan dan memahami simbol aljabar, berupa variabel, konstanta, suku, faktor, dan operasinya menjadi landasan siswa dalam mempelajari aljabar tingkat selanjutnya (Wardhani, 2004). Operasi perkaliannya dapat diselesaikan dengan manipulasi dari hukum distributive terhadap penjumlahan atau pengurangan dan skema geometris (Barnard, 2002).

Saat ini, pembelajaran aljabar mendapatkan perhatian dunia baik pada aspek tujuan pembelajaran aljabar, pendekatan yang digunakan maupun hasil belajar. Selain itu, aljabar juga menjadi perdebatan di berbagai Negara. Hal yang paling penting didebatkan adalah hubungan keterampilan procedural dan pemahaman konsep dalam belajar mengajar aljabar. Aljabar digunakan sebagai salah satu tes masuk perguruan tinggi di beberapa Negara. Hasilnya kemampuan aljabar yang kurang memuaskan. Guru sekolah menengah dituduh bersikap lunak terhadap keterampilan mengajar sehingga berakibat penurunan keterampilan aljabar dan bahkan untuk mengenali hubungan 144 dengan 12 atau $\frac{12}{16}$ dengan $\frac{3}{4}$ (Drijvers,2011).

Dalam pembelajaran aljabar, banyak siswa yang belajar aljabar dalam keadaan kurang pemahaman operasi aritmatika. Jupri mengkategorikan 5 (lima) kelompok kesulitan siswa yaitu 1. Aplying arithmetic operation (ARITH), 2. Understanding the notion of variable (VAR), 3. Understanding algebraic expression (AE), 4. Understanding the different meaning of the equal sign (EQS), 5. Mathematization difficulties (MATH). (Jupri, Drijvers, \& Heuvel-Panhuizen, 2012). Menurut (Radford, 2012), salah satu penyebab kesulitan - kesulitan 
tersebut diatas adalah karena sifat aljabar yang abstrak sehingga menjadi salah satu cabang matematika sekolah yang menakutkan. Untuk itu diperlukan kondisi yang adem dan mengasikkan agar siswa dapat belajar lebih bermakna, misalnya dengan belajar sambil bermain dan menggunakan metode bervariasi (Putri, 2011), (kurniawati, 2016) menyatakan bahwa Faktor-faktor yang menyebabkan siswa mengalami kesukaran dalam memecahkan soal operasi hitung aljabar diantaranya: kurangnya minat siswa, cara belajar siswa yang cenderung menghafalkan materi sehingga tidak ada konsep yang jelas, kebingungan dalam konsep pengerjaan, prosedur pengerjaan yang ribet dan panjang, siswa malas membaca text soal, kurang ketelitian siswa saat mengerjakan, kurang cermat dalam memahami kata demi kata pada soal, siswa jarang melakukan latihan soal, siswa belum memahami materi prasyarat mengenai bilangan bulat, motivasi belajar kurang, suasana kelas yang tidak nyaman dan strategi pembelajaran yang monoton, ditambahkan juga oleh Lorenzo J.Blanco dan Manuel Garrote (2007) yang mengatakan bahwa ada dua tipe kesulitan siswa pada menyelesaikan soal persamaan aljabar yang pertama kemampuan siswa terhadap materi dasar aritmatika yang kurang menyebabkan siswa melakukan kesalahan dan disisi lain pemahaman konsep siswa terhadap proses aljabar.

Pengetahuan konseptual dalam matematika merupakan pengetahuan dasar yang menghubungkan antara potongan-potongan informasi yang berupa fakta, skill (keterampilan), konsep, atau prinsip (Hiebert dan Wearne, 1986)

(Freudenthal, 2002) proses belajar hanya akan terjadi ketika pengetahuan yang dipelajari bermakna bagi siswa. Menurut Zulkardi (2002) (PMRI) merupakan pendekatan pembelajaran yang mengkaitan antara konteks dengan pembelajaran sehingga dapat tercapai pembelajaran yang berfaedah. konteks digunakan sebagai langkah titk awal untuk membangun konsep matematika.

Wijers (www.fi.uu.nl/publicaties) menyebutkan:

"Students had difficulties mastering the abstrack algebratic skills and teachers had a hard time trying ti give sense to the abstract algebra. A new more sense making algebra program based on the principles of PMRI was believed to overcome these difficulties".

PMRI diyakini memberikan penyelesaian terhadap kesulitan-kesulitan dalam proses belajar aljabar. Hal ini disebabkan PMRI digunakan untuk membangun kembali konsep-konsep matematika yang memaafkan kehidupan sehari-hari. PMRI memandang bahwa matematika adalah aktivitas manusia (mathematic is human activity) sehingga PMRI menggunakan konteks riil sebagai titik awal dalam pembelajaran aljabar. Witzel (2003) dalam penelitiannya disimpulkan bahwa pembelajaran aljabar dengan menggunakan benda konkret dan gambar untuk merepresentasikan matematika yang lebih komplek memberikan hasil yang lebih baik. Penggunaan konteks riil dapat membantu peserta didik dalam memahami konsep matematika sebelum menuju ke pemahaman formal. Dengan menggunakan pendekatan PMRI diharapkan peserta didik dapat lebih mudah memahami operasi bentuk aljabar dan berbagai kesulitan yang dialami 
peserta didik dapat terselesaikan. air merupakan konteks yang digunakan dalam perkalian aljabar.

Pada penelitian ini, konteks yang digunakan sebagai suatu perkenalan ataupun situasi awal dalam pembelajaran adalah dengan menggunakan konteks yang ada disekitar kita yaitu batu, minyak dan air.

Mendesain hipotesis lintasan pembelajaran atau Hypothetical Learning Trajectory (HLT) dari pengetahun informal (informal knowledge) dan pengetahuan awal (pre knowledge) yang dimiliki siswa kemudian berkembang menjadi suatu pengetahuan formal matematika melalui suatu proses pemodelan merupakan inti dari penelitian ini. Sehubungan dengan itu peneliti tertatik untuk melakukan penelitian dengan judul: "Desain Pembelajaran Operasi Aljabar Perkalian dengan Menggunakan Konteks Air, Minyak dan Batu Siswa Kelas”.

\section{METODE PENELITIAN}

Design research yang dipakai dalam penelitian ini menggunakan type validation studies yang bertujuan untuk membuktikan teori-teori pembelajaran (Nieveen, McKenney, Akker, 2006: 152). Proses penelitian pada design research meliputi tahapan (Gravemeijer and Cobb 2006).

Tahap pertama: preparing for the experiment/preliminary design (persiapan untuk penelitian/desain pendahuluan). Pada tahap ini dilakukan kajian literatur mengenai materi pembelajaran yaitu tentang perkalian aljabar, pendidikan matematika realistik, dan metode design research sebagai dasar perumusan dugaan strategi awal siswa dalam pembelajaran atau sebagai landasan dalam mendesain lintasan belajar. Selanjutnya akan didesain hypothetical learning trajectory (HLT). Hipotesis lintasan belajar ini dikembangkan berdasarkan literatur dan disesuaikan dengan pembelajaran yang sebenarnya selama percobaan mengajar (teaching experiment).

Tahap kedua: the design experiment (desain percobaan). Pilot experiment dilakukan untuk mengujicobakan HLT yang telah dirancang pada siswa dalam kelompok kecil guna mengumpulkan data dalam menyesuaikan dan merevisi HLT awal untuk digunakan pada tahap teaching experiment nantinya. Siswa yang dilibatkan dalam pilot experiment sebanyak 6 siswa yang terdiri dari tingkat kemampuan yang berbeda dan peneliti akan berperan sebagai guru. Pengambilan subjek 6 orang siswa ini berdasarkan hasil diskusi dengan Ibu Roslina, S.Pd guru kelas VII.2

Tabel 1. Nama Siswa pada Pilot Experiment

\begin{tabular}{clc}
\hline No. & \multicolumn{1}{c}{ Nama Siswa } & Kemampuan \\
\hline 1 & Maria al-qiptiah & Tinggi \\
\hline 2 & Balqis salsabila & Tinggi \\
\hline 3 & Septa oktavianto & Sedang \\
\hline 4 & Wawan apriadi & Sedang \\
\hline 5 & lindawati & Rendah \\
\hline 6 & Mayasari & Rendah \\
\hline
\end{tabular}

Tahap ketiga: retrospective analysis. Pada tahap ini, data yang diperoleh dianalisis dan hasil analisis ini digunakan untuk merencanakan kegiatan dan mengembangkan rancangan kegiatan pada pembelajaran berikutnya. Pada tahap 
ini, HLT dibandingkan dengan pembelajaran siswa yang sebenarnya, hasilnya digunakan untuk menjawab rumusan masalah.

Penelitian ini dilakukan pada semester genap tahun akademik 2016/2017. Subjek yang dilibatkan dalam penelitian ini adalah 6 orang siswa kelas VII SMP N 5 Palembang. Data yang diperoleh dianalisis secara retrospektif bersama HLT yang menjadi acuannya. Analisis data diikuti oleh peneliti dan bekerja sama dengan pembimbing untuk meningkatkan reliabilitas dan validitas pada penelitian ini.

Teknik pengumpulan data yaitu rekaman video, observasi, wawancara, dokumentasi, catatan lapangan dan tes tertulis yang dikumpulkan dan dianalisis untuk memperbaiki HLT

\section{HASIL PENELITIAN DAN PEMBAHASAN \\ Hasil Penelitian}

Penelitian ini menghasilkan lintasan belajar pada pembelajaran perkalian aljabar siswa di kelas VII, yaitu Mengenalkan benda-benda disekitar yang bisa digunakan dalam pembelajaran perkalian aljabar seperti minyak, batu dan air, Menemukan Konsep Perkalian Aljabar serta menyelesaikan permasalahan yang berhubungan dengan kehidupan sehari - hari.

\section{Pembahasan}

Berdasarkan dari hasil yang diperoleh, maka bagian pembahasan ini membahas tentang jawaban dari rumusan masalah penelitian yang diajukan, yaitu:

1. Mengetahui pemahaman siswa pada pembelajaran melalui Hypothetical Learning Trajectory (HLT) yang telah didesain dengan menggunakan konteks air, minyak dan batu.

2. Menghasilkan lintasan belajar siswa pada pembelajaran menggunakan konteks air dapat berkembang dari tahap informal ke formal.

Dalam pembelajaran aljabar, banyak siswa yang belajar aljabar dalam keadaan kurang pemahaman operasi aritmatika. Jupri mengkategorikan 5 (lima) kelompok kesulitan siswa yaitu 1. Aplying arithmetic operation (ARITH), 2. Understanding the notion of variable (VAR), 3. Understanding algebraic expression (AE), 4. Understanding the different meaning of the equal sign (EQS), 5. Mathematization difficulties (MATH). (Jupri, Drijvers, \& Heuvel-Panhuizen, 2012). Menurut (Radford, 2012), salah satu penyebab kesulitan - kesulitan tersebut diatas adalah karena sifat aljabar yang abstrak sehingga menjadi salah satu cabang matematika sekolah yang menakutkan.

Untuk itu diperlukan kondisi yang nyaman dan menyenangkan agar siswa dapat belajar lebih bermakna, misalnya dengan belajar sambil bermain dan menggunakan metode bervariasi (Putri, 2011), (kurniawati, 2016) menyatakan bahwa Faktor-faktor yang menyebabkan siswa mengalami kesulitan dalam menyelesaikan soal operasi hitung aljabar diantaranya: kurangnya minat siswa, cara belajar siswa yang cenderung menghafalkan materi sehingga tidak ada konsep yang jelas, kebingungan dalam konsep pengerjaan, prosedur pengerjaan 
yang ribet dan panjang, siswa malas membaca text soal, kurang ketelitian siswa saat mengerjakan, kurang cermat dalam memahami kata demi kata pada soal, siswa jarang melakukan latihan soal, siswa belum memahami materi prasyarat mengenai bilangan bulat, motivasi belajar kurang, suasana kelas yang tidak nyaman dan strategi pembelajaran yang monoton.

Ditambahkan juga oleh Lorenzo J.Blanco dan Manuel Garrote (2007) yang mengatakan bahwa ada dua tipe kesulitan siswa pada menyelesaikan soal persamaan aljabar yang pertama kemampuan siswa terhadap materi dasar aritmatika yang kurang menyebabkan siswa melakukan kesalahan dan disisi lain pemahaman konsep siswa terhadap proses aljabar.

Operasi perkaliannya dapat diselesaikan dengan manipulasi dari hukum distributive terhadap penjumlahan atau pengurangan dan skema geometris (Barnard, 2002).

Semua aktivitas dilakukan dengan kerja kelompok, hal ini bertujuan agar siswa mampu berkomunikasi dan bekerja sama dalam tim. Tiap kelompok terdiri dari tiga orang siswa dengan tingkat kemampuan yang berbeda, sehingga pada tahap ini 6 siswa dibagi menjadi 2 kelompok.

Dalam menjawab pertanyaan dari rumusan masalah, peneliti akan merujuk pada hasil analisis retrospektif sebelumnya. Akan dibahas secara runut seperti di bawah ini:

\section{Aktivitas 1 : Mengenalkan Benda-Benda Disekitar Yang Bisa Digunakan Dalam Pembelajaran Perkalian Aljabar Seperti Minyak, Batu Dan Air}

Pada awal aktivitas, siswa secara berkelompok antusias memperhatikan guru mencampurkan benda-benda yang telah disediakan sehingga siswa dapat melihat apa yang terjadi setelah dilakukan pencampuran air, minyak dan batu dengan petunjuk Lembar Aktivitas Siswa (LAS 1)

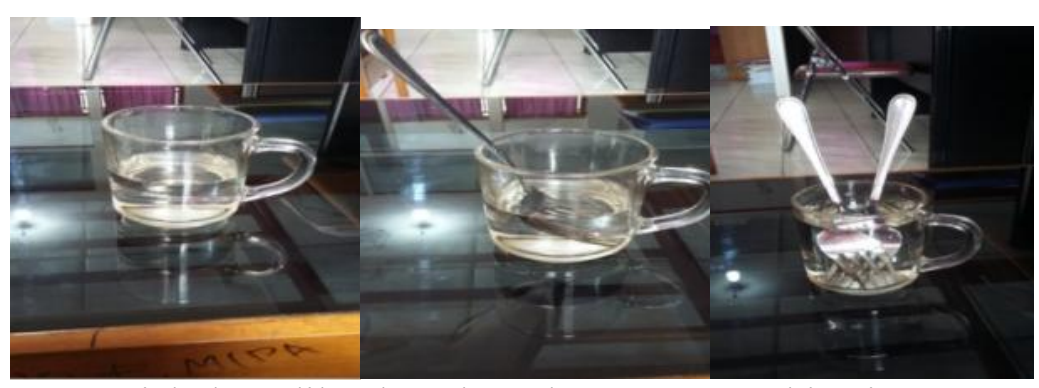

Gambar 1. Variabel X dilambangkan dengan secangkir air, X pangkat 1 dilambangkan dengan secangkir air dan pangkatnya 1 garpu dan $\mathrm{X}$ pangkat 2 dilambangkan dengan secangkir air dan pangkatnya 2 garpu 


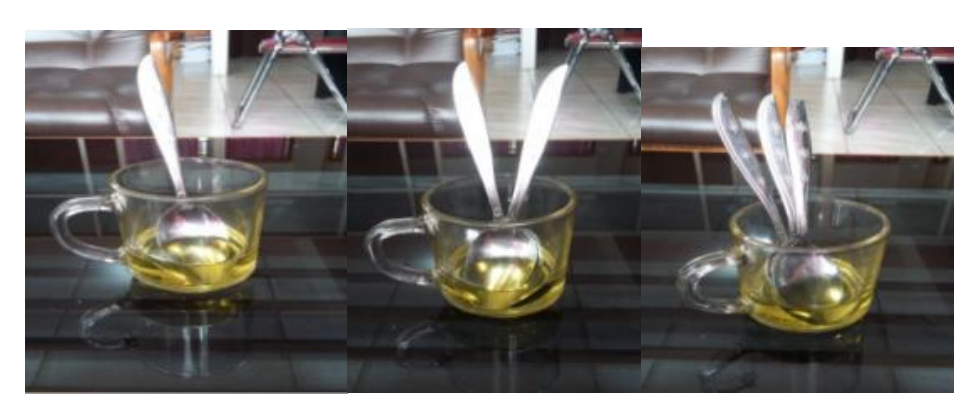

Gambar 2. Variabel Y pangkat 1 dilamabangkan dengan secangkir minyak dan pangkatnya 1 sendok, Y pangkat 2 dengan secangkir minyak dan pangkatnya 2 sendok dan Y pangkat 3 dengan secangkir minyak dan pangkat 3 sendok

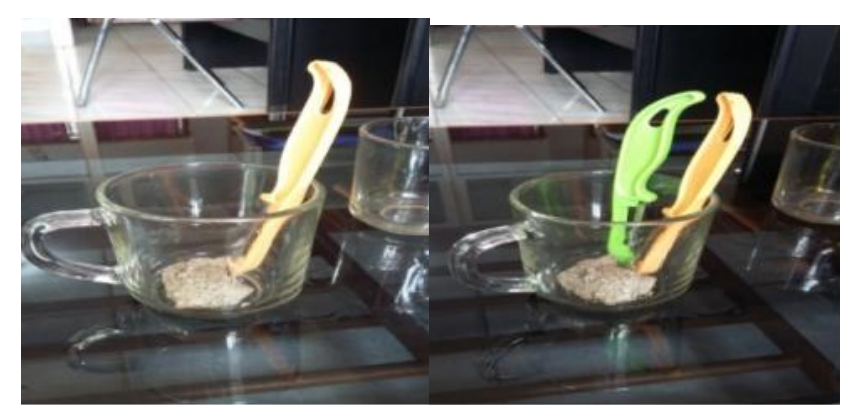

Gambar 3. Variabel Z pangkat 1 dilambangkan dengan secangkir batu dan pangkatnya 1 pisau buah dan variabel $Z$ pangkat 2 dilambangkan dengan secangkir batu dan pangkatnya 2 pisau buah.

Pada saat kerja kelompok, siswa mulai saling berdiskusi dan bertanya dengan teman. Guru (peneliti) sebagai fasilitator, melihat pekerjaan setiap kelompok dan memberikan arahan terhadap pertanyaan yang mereka berikan.

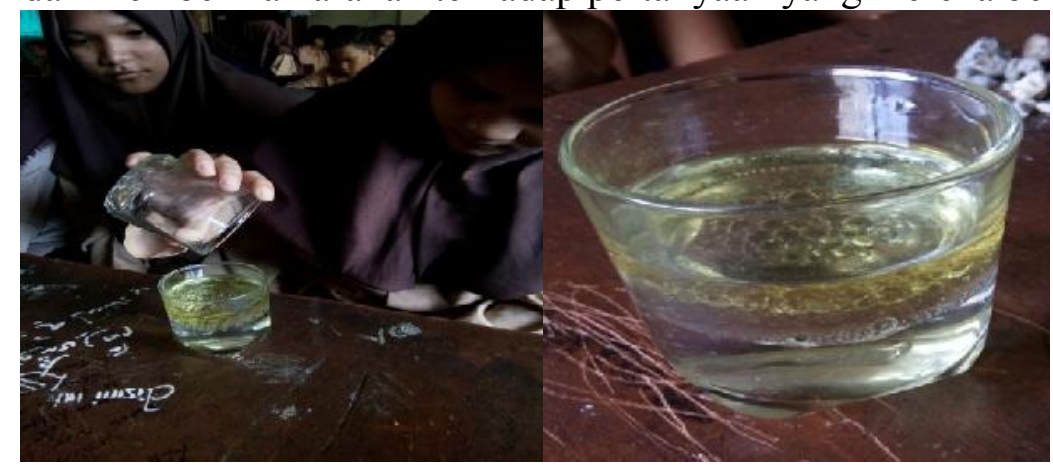

Gambar 4. Siswa mencampur benda dan melihat hasil

Dari percobaan yang telah dilakukan siswa, pada percobaan yang pertama yaitu mencampurkan air dan minyak, siswa bisa melihat bahwa minyak tidak akan pernah bercampur dengan air artinya X dikalikan Y maka hasilnya XY 


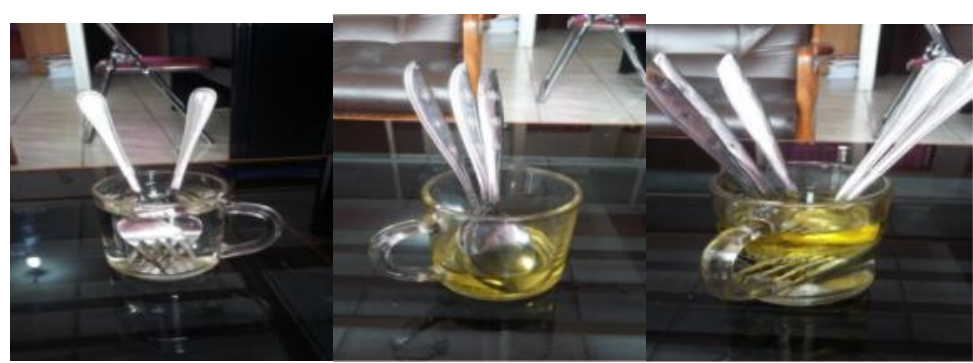

Gambar 5. Percobaan siswa dengan variabel beda

Begitu juga pada percobaan kedua secangkir air dengan 2 garpu apabila dikalikan dengan secangkir minyak dengan 3 sendok maka hasilnya air dengan 2 garpu dan minyak dengan 3 sendok itu artinya $\mathrm{X}^{2}$ dikalikan dengan $\mathrm{Y}^{3}$ maka hasilnya $\mathrm{X}^{2} \mathrm{Y}^{3}$. Apabila perkalian aljabar dengan menggunakan variabel yang sama maka menghasilkan percobaan seperti ini

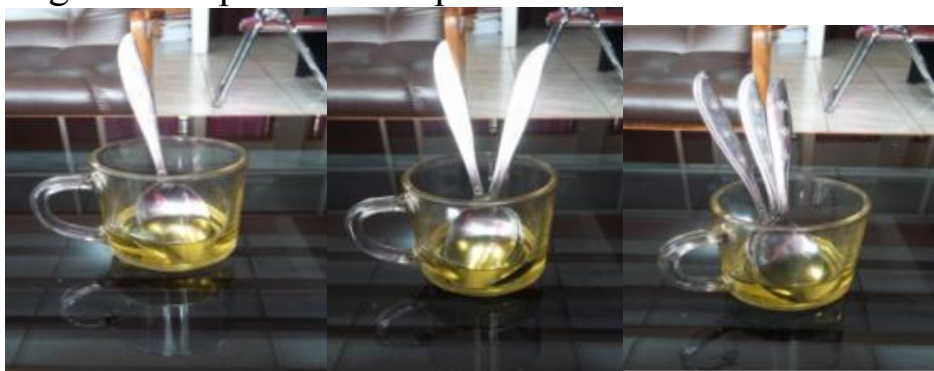

Gambar 6. Pecobaan siswa dengan variabel sama

Dari percobaan ini siswa bisa mengambil kesimpulan bahwa $\mathrm{Y}^{1}$ dikalikan dengan $\mathrm{Y}^{2}$ maka hasilnya $\mathrm{Y}^{2+1}=\mathrm{Y}^{3}$ oleh karena itu sifat perkalian aljabar $\mathrm{P}^{\mathrm{a}} \times \mathrm{P}^{\mathrm{b}}$ $=\mathrm{P}^{\mathrm{a}=\mathrm{b}}$

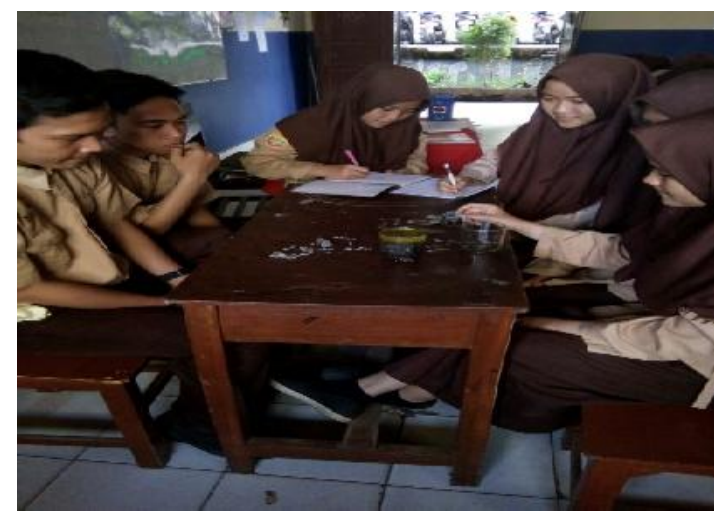

Gambar 7. Siswa mencampur benda dan melihat hasil 


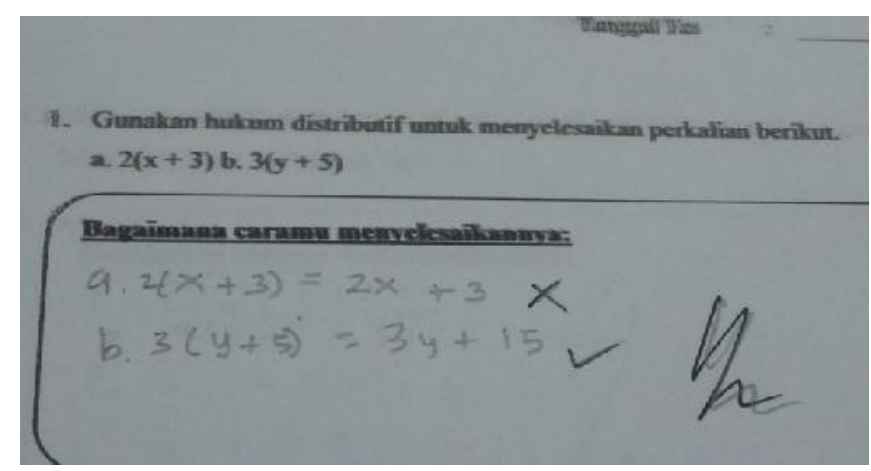

Gambar 8. Jawaban tiap kelompok no. 1

Pemahaman siswa pada aktivitas 1 dilihat dari kemampuan siswa mencampur minyak dengan air, minyak dengan batu ataupun sebaliknya sehingga siswa bisa melihat apa yang terjadi dari pencampuran dua benda tersebut. Hal tersebut sesuai dengan konjektur yang telah diprediksi peneliti.

\section{Aktivitas 2 : Menemukan Konsep Perkalian Aljabar}

Pada aktivitas kedua, kegiatan yang dilakukan adalah menemukan konsep perkalian aljabar. LAS 2 terdiri dari $2 \mathrm{X}$ percobaan dan 6 permasalahan yang harus mereka kerjakan. Ketika guru memberi petunjuk pada kelompok 2 yaitu , kelompok 1 pun ikut memperhatikan arahan dari guru. Sehingga mereka juga melakukan arahan dari guru

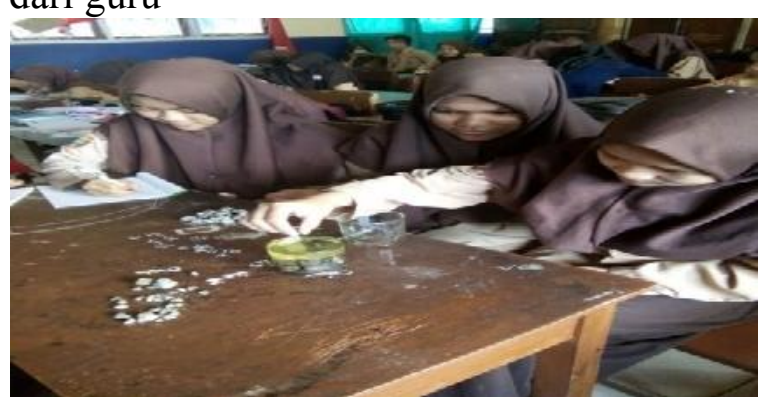

Gambar 9. Setiap Kelompok Memperhatikan petunjuk guru

Setelah siswa melakukan percobaan pencampuran benda-benda tadi siswa diajak mengingat dan mengaitkan dengan pembelajaran perkalian aljabar yaitu apabila perkalian antara air dan minyak maka hasilnya air dan minyak begitu juga dengan perkalian antara $\mathrm{x}$ dan $\mathrm{y}$ maka hasilnya $\mathrm{xy}$. sehingga siswa bisa menemukan sendiri konsep perkalian aljabar. Pada LAS 2, aktivitas ditujukan untuk melihat alur berfikir siswa bagaimana menentukan hasil perkalian aljabar dari percobaan yang telah mereka lakukan.

Beberapa jawaban tiap kelompok : 


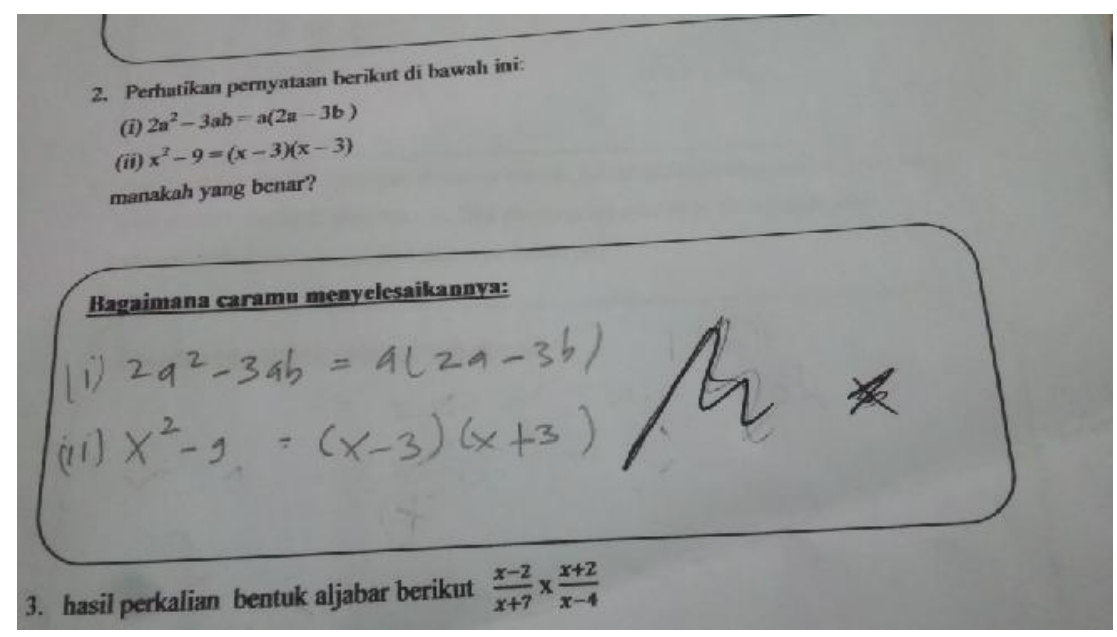

Gambar 10. Jawaban Tiap Kelompok

Pada gambar 10, terlihat pemahaman siswa tentang konsep perkalian aljabar. siswa menentukan dapat menentukan strategi hitung yang baik pada permasalahan yang diberikan. Hal tersebut sesuai dengan konjektur yang telah diprediksi peneliti

\section{Aktivitas 3 : Menyelesaikan Permasalahan}

Aktivitas ketiga LAS 3 terdiri dari 5 soal essay mengenai perbandingan senilai yang berhubungan dengan kehidupan sehari - hari siswa. Pertama guru meminta siswa untuk membaca dan memahami soal yang ada pada LAS 3 tersebut, guru meminta agar siswa benar- benar memahami terlebih dahulu maksud soal tersebut.

Soal nomor 4. Paman memiliki sawah yang berbentuk persegi panjang dengan panjang $(4 \mathrm{x}+2) \mathrm{cm}$ dan lebar $(2 \mathrm{x}+1) \mathrm{cm}$. berapakah luas sawah paman?

Setiap kelompok membaca dan memahami setiap permasalahan yang ada pada LAS 3. Mereka antusias dalam menyelesaikan setiap permasalahan yang ada, mereka pun berdisuki dan bekerja sama di dalam kelompok masing - masing. Berikut alternatif jawaban tiap kelompok untuk soal no 4

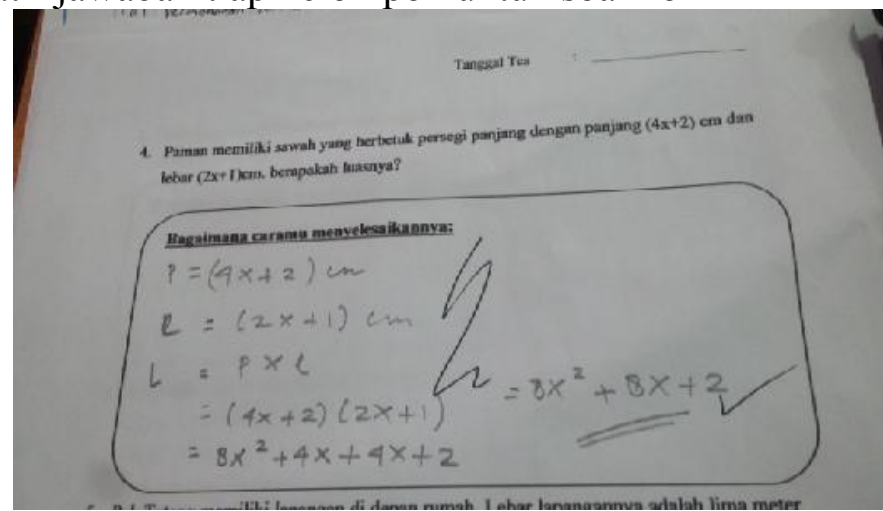

Gambar 11. Alternatif Jawaban Tiap Kelompok No

Pada gambar 11. terlihat Alternatif jawaban kedua kelompok sudah sesuai dengan harapan peneliti, mereka benar dalam memahami maksud soal dan benar dalam memberikan alternatif jawaban. Pada aktivitas 3 ini siswa diberikan 5 soal 
yang berhubungan dengan kehidupan sehari - hari siswa, mereka dituntut untuk bekerja sama dalam menyelesaikan permasalahan yang ada. Awalnya mereka kesulitan dalam memahami maksud soal, tetapi setelah dijelaskan oleh guru mereka mampu menyelesaikannya

\section{SIMPULAN DAN SARAN}

Berdasarkan hasil penelitian dan pembahasan yang telah diuraikan, peneliti dapat menyimpulkan bahwa serangkaian aktivitas yang telah didesain, lintasan belajar yang dihasilkan dalam penelitian ini adalah lintasan - lintasan yang dilalui siswa melalui tiga aktivitas yaitu Mengenalkan benda-benda disekitar yang bisa digunakan dalam pembelajaran perkalian aljabar seperti minyak, batu dan air, pemahaman awal dalam pembelajaran perkalian aljabar, Aktivitas menemukan konsep perkalian aljabar ,serta aktivitas ketiga menyelesaikan permasalahan yang bertujuan untuk melihat perkembangan pembelajaran siswa melalui serangkaian aktivitas yang telah dilalui siswa. Melalui rangkaian aktivitas tersebut dapat membantu siswa memahami materi perkalian aljabar. Siswa diajak untuk mengeksplorasi kemampuan yang dimiliki dan terlibat secara langsung dalam memahami konsep perkalian aljabar. Dimana dalam setiap aktivitasnya siswa dituntut untuk bekerja sama, mampu mengkomunikasikan gagasan yang dimiliki sehingga siswa senantiasa dapat berbagi dan bertukar informasi yang mereka miliki

\section{DAFTAR PUSTAKA}

Bakker, A. (2004). design reseach in statistics education on symbolizing and computer tools. ultrecht: wilco press, Amesfoot.

Barnar, T. (2002). Hurdles and strategies in the teaching of algebra.

Blanco, L. a. (2007). Difficulties in Learning Inequalities in Students of the First Year of Pre-University Education . Eurasia Journal of Mathematics, Science and Technology Education, 3(3), in Spain. , 221-229.

Facruddin.D. (n.d.). Desain pembelajaran penyelesaian persamaan kuadrat melalui metode"Naive Geometry" untuk siswa kelas VIII SMP. JPM unsri , 2014.

Freudenthal, H. (2002). Revisiting Mathematics Education. Gravemeijer, K. C. (2006). Desain Reseach from a Learning Design perspective. Educational Design Reseach.

Gravemeijer, K. (1994). Developing Realistic mathematics Education. Utrecht: Technipress, culemborg.

Gustiati. (2000). Efektivitas Pembelajaran Matematika dengan Menggunakan Alat Peraga berupa Benda Model . Makassar: FMIPA UNM .

Hiebert, J. d. (1986). Procedure Over Concept: The Acquistion of Decimal Number.

Jamal, F. (2014). Analisis Kesulitan Belajar Siswa dalam Mata Pelajaran Matematika pada Materi Peluang Kelas IX IPA SMA Muhammadiyah Meulaboh Johan Pahlawan. Jurnal Pendidikan Matematika, 18-36. 
Jupri, A. D.-P. (2012). Investigating Indonesian students' difficulties in initial algebra.

dari

dspace.library.uu.n:dspace.library.uu.nl/bitstream/1874/272369/1/121020 12.pdf. jakarta: UT

Kurniawati, D. (2016). kesulitan siswa dalam menyelesaikan soal operasi bentuk aljabar pada siswa SMP. USM Surakarta.

McClu (Jupri, D. \&.-P. (2012). A Study On The Use of Manipulatives and Their Effect o Student Achievements in a High School ALgebra I Class. (E. D. 077, Penyunt.)http://nycdoeit.airws.org/pdf/Algeblocks.pdf.

Putri, R. I. (2011). Improving Mathematics Communication Ability of Student in GRade 2 Through PMRI Approach. Departement Mathematics of Education Sriwijaya University. Inderalaya.

Radford, L. (2012). Early ALgebra Thinking Epistemological, Semioti12th International Congress on Mathematical Education. Seoul: ICME-12, .

Wardhani, S. (2004). Permasalahan Kontekstual Mengenalkan Aljabar di SMP. yogyakarta: Depdiknas Dirjen Pendidikan Dasar dan Menengah PPPG Matematika. .

Widyantini, T. d. (2010). Penggunaan Alat Peraga dalam Pembelajaran Matematika di SMP. . Yogyakarta: Pusat pengembangan pemberdayaan pendidik dan tenaga kependidikan Matematika (PPPPTK) Matematika.

Wijaya, A. (2012). Pendidikan Matematika Realistik: Suatu Alternatif Pendekatan Pembelajaran Matematika, . Yogyakarta, Graha Ilmu.58, 21-23.

Zulkardi. (2002). Zulkardi. (2002). Developing A Learning Environment on Realistic Mathematics Education For Indonesian Student Teachers. Twente Unv. Enschede: Doctoral Thesis of Twente University 